\title{
Retrolental fibroplasia-controlled study of 4 years' experience in a neonatal intensive care unit
}

\author{
V Y H YU, D M HOOKHAM, AND J R M NAVE \\ Department of Paediatrics, Queen Victoria Medical Centre, Melbourne, Australia
}

SUMmaRY During the 4 years 1977-80, 14 infants developed retrolental fibroplasia (RLF) in the neonatal unit at this medical centre. All were very low birthweight (VLBW) infants who weighed $1500 \mathrm{~g}$ or less at birth. The incidence of RLF was $3.5 \%$ for all VLBW infants admitted for neonatal intensive care and $4.7 \%$ for VLBW survivors. The mean birthweight of the affected infants was 970 (range 730-1310) $\mathrm{g}$ and mean gestational age 26 (range 24-29) weeks. Seven of the affected infants $(2.4 \%$ of VLBW survivors) had significant scarring with temporal dragging of the optic disc and retinal detachment. Each of the 14 infants was matched with 2 control infants in order to see whether any factors predisposing to the development of RLF, including those related to oxygen therapy and monitoring, could be identified. The only factor associated with RLF was a higher volume of blood given with replacement transfusions. The occurrence of RLF was unrelated to an increase in requirement for or duration of oxygen therapy, arterial oxygen tensions as determined by intermittent sampling, or the availability of transcutaneous oxygen monitoring. The care taken in oxygen therapy may have been responsible for failure to show a quantitative association between hyperoxaemia and RLF. Although the problem of oxygen therapy in preterm infants is far from being resolved, current neonatal intensive care methods have limited the occurrence of RLF to VLBW infants. This study demonstrated a lower incidence of RLF in VLBW infants despite an improved survival rate compared with that previously reported.

The extensive literature on the history of oxygen therapy and retrolental fibroplasia (RLF) which dated back to the early 1940s has been reviewed by the Committee on Fetus and Newborn of the American Academy of Pediatrics, which also established guidelines on oxygen use in the newborn infant. ${ }^{1}$ Despite the most vigorous monitoring during oxygen therapy, a recent study has shown a resurgence of RLF in very low birthweight (VLBW) survivors. ${ }^{2}$ In the multi-centred co-operative study of RLF conducted between 1969 and 1972, the incidence of RLF was shown to be inversely correlated with birthweight and gestational age and the strongest association found, apart from birthweight, was with duration of oxygen therapy. ${ }^{3}$ The problem of oxygen therapy for preterm infants is far from being resolved as the pathogenesis of RLF is still imperfectly understood. This condition has been reported to occur without oxygen administration, 45 in term infants, ${ }^{6-8}$ in anencephalic infants at birth, ${ }^{9}$ and in a child with cyanotic heart disease. ${ }^{10}$ Conversely, sustained hyperoxaemia in preterm infants may not result in RLF.11 Additional factors which have been suggested include iron and water-soluble vitamins, ${ }^{12}$ chronic hypoxia in-utero, ${ }^{13}$ vitamin $\mathrm{E}$ deficiency, ${ }^{14}$ exchange or replacement transfusion with blood containing adult haemoglobin, ${ }^{2}{ }^{15}$ and treatment with indomethacin for patent ductus arteriosus. ${ }^{16}$ In the present study, details of infants with RLF admitted to the neonatal unit at this medical centre during a 4-year period are reported. In order to obtain information about possible predisposing factors, clinical data from the affected infants and from a control group were compared.

\section{Patients and methods}

Ophthalmological examination. VLBW infants who weighed $1500 \mathrm{~g}$ or less at birth, infants who required assisted ventilation, and those who needed prolonged oxygen therapy, especially for recurrent apnoea, had routine ophthalmological examination. Indirect ophthalmoscopy was performed by one of us (JRMN) at approximately weekly intervals, after oxygen therapy was stopped or within a fortnight after birth if the infant was still on supplemental 
oxygen. For extremely preterm infants, examinations were carried out from the time the tunica vasculosa lentis began to clear. The pupils were maximally dilated for these examinations. Any infant who showed evidence of RLF had regular ophthalmological examinations as an outpatient after his discharge from hospital. The classification used for evolutionary lesions of RLF was Keith's modification $^{17}$ of Kingham's system. ${ }^{18}$ Cicatricial RLF changes were graded by using Keith's classification. ${ }^{17}$ A description of the eye changes for stages of development and grades of resolution and scarring is summarised in Table 1.

Neonatal care. Arterial oxygen pressure $\left(\mathrm{PaO}_{2}\right)$ measurements were made from blood samples taken from indwelling umbilical artery catheters or by percutaneous puncture of peripheral arteries. The inspired oxygen concentration was regulated to produce $\mathrm{a} \mathrm{PaO}_{2}$ in the range of $50-100 \mathrm{mmHg}$. Umbilical artery catheters were left in situ for an average of 5 days followed by peripheral artery sampling and transcutaneous oxygen monitoring which was often continued for several weeks. Indications for assisted ventilation and protocol for management of respiratory failure have been previously reported. ${ }^{19}$ Blood transfusions were given in infants with cardiorespiratory distress if haematocrit was $<40 \%$, if systolic blood pressure was $<40 \mathrm{mmHg}$, or if $>10 \%$ of the blood volume had been taken for blood tests. Exchange transfusions were carried out if the bilirubin concentration reached 200-300 $\mu \mathrm{mol} / \mathrm{l}(11 \cdot 7-17.5 \mathrm{mg} / 100 \mathrm{ml})$ depending on the presence of risk factors for kernicterus. VLBW infants received an oral daily supplement of $20 \mathrm{IU}$ vitamin $\mathrm{E}$ after full oral feeds had been established;

Table 1 Developing and cicatricial changes in retrolental fibroplasia ${ }^{18}$

\footnotetext{
Stages of development

I Abnormal terminal branching of temporal vessels. Abrupt margin between vascularised and non-vascularised retina

II Vessels dilated, some parallel to ora serrata. Distinct vascular mesenchymal shunt parallel to ora temporally, forming slight shelf

III Shunt forms distinct shelf into vitreous cavity with dilated sinusoids on surface. Neovascularisation from posterior edge of shelf. Haemorrhages

IV Retina detached from temporal arcades to ridge. Retinal vessels leave retina and run straight to ridge

V Retina detached from disc to ora

Grades of resolution and scarring

I Normal or mild peripheral changes

II Slight dragging of temporal vessels. Heterotopia of macula. Preretinal fibrosis. Myopia

III Dragged disc with fibrous tissue in temporal periphery

IV Retinal fold with fibrous tissue on posterior surface of lens

V Peripheral ring-shaped retinal detachment

VI Total funnel-shaped retinal detachment
}

before this parenteral nutrition (which did not contain vitamin E) was given. ${ }^{20}$ In addition, oral daily supplements of Pentavite* $0.45 \mathrm{ml}$ were given after the establishment of full oral feeds and Fergon $\dagger 1 \mathrm{ml}$ was started at 6 weeks after birth. Both RLF and control groups therefore received the same supplements. Details of supportive management for infants admitted to the neonatal unit and treatment protocol for patent ductus arteriosus, particularly regarding treatment with indomethacin, have been previously summarised..$^{21} 22$

Controls. For each RLF infant, 2 control infants were chosen from the survivors, who were admitted immediately before or after each RLF infant, matched on the basis of a birthweight within $200 \mathrm{~g}$ of that of the RLF infant, and the need for oxygen therapy or assisted ventilation.

Collection of perinatal data was carried out prospectively for all VLBW infants as part of the growth and development follow-up programme. This source of information was used for reviewing factors which might have had an influence on the development of RLF. Statistical analysis was with the Student's $t$ test and the $\chi^{2}$ test.

\section{Results}

Incidence. During the 4-year period, January 1977 to December 1980, 14 infants were diagnosed as having RLF. The mean birthweight of the affected infants was 970 (range 730-1310) $\mathrm{g}$ and mean gestational age 26 (range 24-29) weeks. Of the 411 VLBW infants seen at the medical centre during the same period, 22 died in the delivery room and 14 were not offered treatment because of major congenital malformations evident at birth. The incidence of RLF in the 375 VLBW infants admitted for neonatal intensive care was therefore 3.5\%. Among the 297 VLBW survivors the incidence was $4.7 \%$. The incidence of RLF in infants weighing $501-1000 \mathrm{~g}$ and $1001-1500 \mathrm{~g}$ and the occurrence of grades I-VI RLF in the respective birthweight categories are shown in Table 2. Seven of the 14 affected infants ( $2.4 \%$ of VLBW survivors) had significant scarring with temporal dragging of the optic disc and retinal detachment (grades III-VI).

Progression of eye changes. The first visible sign of developing RLF was detected at a mean age of 54 (range 33-75) days after birth. The abnormality

* Nicholas Pty Ltd, Melbourne, Australia. This contains vitamin A $1620 \mathrm{IU}$, thiamine $0.54 \mathrm{mg}$, riboflavin $0.81 \mathrm{mg}$, pyridoxine $0.13 \mathrm{mg}$, ascorbic acid $42.7 \mathrm{mg}$, vitamin D 405 IU, nicotinamide $7.11 \mathrm{mg}$, pantothenate $0.33 \mathrm{mg}$.

$\dagger$ Winthrop Laboratories, Melbourne, Australia. This contains $6.6 \mathrm{mg}$ of elemental iron. 
Table 2 Incidence and severity of retrolental fibroplasia

\begin{tabular}{|c|c|c|c|c|c|c|c|c|c|}
\hline \multirow{2}{*}{$\begin{array}{l}\text { Birthweight } \\
(g)\end{array}$} & \multicolumn{2}{|c|}{ Incidence in infants of very low birthweight } & \multicolumn{6}{|c|}{$\begin{array}{l}\text { Number of infants with grades } \\
\text { of resolution and scarring }\end{array}$} & \multirow{2}{*}{$\begin{array}{l}\text { Incidence in VLBW } \\
\text { neonatal survivors } \\
\text { (grades III-VI) }\end{array}$} \\
\hline & $\begin{array}{l}\text { In those admitted for } \\
\text { intensive care }\end{array}$ & In survivors (all grades) & $I$ & II & III & IV & $\boldsymbol{V}$ & $V I$ & \\
\hline $\begin{array}{r}501-1000 \\
1001-1500\end{array}$ & $\begin{array}{l}8 / 107(7 \cdot 5) \\
6 / 268(2 \cdot 2)\end{array}$ & $\begin{array}{l}8 / 60(13 \cdot 3) \\
6 / 237(2 \cdot 5)\end{array}$ & $\begin{array}{l}2 \\
1\end{array}$ & $\begin{array}{l}4 \\
0\end{array}$ & $\begin{array}{l}\mathbf{0} \\
2\end{array}$ & $\begin{array}{l}0 \\
1\end{array}$ & $\begin{array}{l}\mathbf{0} \\
\mathbf{0}\end{array}$ & $\begin{array}{l}2 \\
2\end{array}$ & $\begin{array}{l}2 / 60(3 \cdot 3) \\
5 / 237(2 \cdot 1)\end{array}$ \\
\hline Total & $14 / 375(3 \cdot 5)$ & $14 / 297(4 \cdot 7)$ & 3 & 4 & 2 & 1 & 0 & 4 & $7 / 297(2 \cdot 4)$ \\
\hline
\end{tabular}

Number with RLF/total number, percentages in parentheses.

reported when RLF was first noted corresponded to stage $I$ in 6 infants, stage II in 5 infants, and stage III in 3 infants. The number of infants with grades I-VI of resolution or scarring who had evolutionary lesions corresponding to stages I-V diagnosed are shown in Table 3. Three of the 4 infants who did not progress beyond stage II had spontaneous regression leading to complete resolution or only mild peripheral changes and myopia. Two of the 6 infants who progressed to stage III ended up in grade VI and blindness, one of whom had this degree of severe change in one eye only. One of the 2 infants with stage IV changes had bilateral grade VI changes and the one infant who progressed to stage $\mathrm{V}$ has a resultant grade VI change. The remaining infant, who had grade IV changes on follow-up examination, was hyperoxaemic on admission at age 6 hours, having been ventilated in $100 \%$ oxygen for recurrent apnoea at a community hospital. She was transferred back to the referring hospital for convalescence at age 10 days when an ophthalmological examination showed stage II changes. Subsequent progression of the acute RLF changes was not monitored after transfer. None of the infants had treatment for his RLF. The 3 infants with bilateral grade VI changes were all born in the first 6 months of the study period.

Comparison with controls. The results of comparisons between RLF infants and controls are given in Tables 4 and 5. Although the incidence of multiplicity of birth, perinatal asphyxia, septicaemia, treatment with indomethacin for patent ductus

Table 3 Ophthalmological outcome. (More severely affected eye)

\begin{tabular}{llllllll}
\hline $\begin{array}{l}\text { Stages of development } \\
(n=14)\end{array}$ & \multicolumn{6}{l}{$\begin{array}{l}\text { Number of infants with grades of } \\
\text { resolution and scarring }\end{array}$} \\
\cline { 3 - 8 } & & $I$ & $I I$ & $I I I$ & $I V$ & $V$ & $V I$ \\
\hline I & $(\mathrm{n}=2)$ & 1 & 1 & 0 & 0 & 0 & 0 \\
II & $(\mathrm{n}=2)$ & 0 & 1 & 1 & 0 & 0 & 0 \\
III & $(\mathrm{n}=6)$ & 2 & 1 & 1 & 0 & 0 & 2 \\
IV & $(\mathrm{n}=2)$ & 0 & 1 & 0 & 0 & 0 & 1 \\
V & $(\mathrm{n}=1)$ & 0 & 0 & 0 & 0 & 0 & 1 \\
Not known & $(\mathrm{n}=1)$ & 0 & 0 & 0 & 1 & 0 & 0 \\
\hline
\end{tabular}

arteriosus, and bronchopulmonary dysplasia was higher in RLF infants than controls, the differences were not statistically significant.

The percentage distribution of exposure to different ranges of oxygen concentration was similar in RLF infants and controls (Fig. 1). The duration

Table 4 Perinatal factors

\begin{tabular}{lccc}
\hline & $\begin{array}{c}R L F \text { infants } \\
(n=14)\end{array}$ & $\begin{array}{c}\text { Controls } \\
(n=28)\end{array}$ & $P$ \\
\hline Birthweight (g, mean \pm SEM) & $970 \pm 50$ & $1010 \pm 30$ & NS \\
Gestation (weeks, mean \pm SEM) & $26 \pm 0 \cdot 4$ & $27 \pm 0 \cdot 3$ & NS \\
Sex ratio (M: F) & $6: 8$ & $11: 17$ & NS \\
Multiplicity of birth (n) & $4(29)$ & $4(14)$ & NS \\
Apgar score $\leqslant 3$ at 5 min (n) & $4(29)$ & $3(12)$ & NS \\
Lowest pH in first 4 days & $7 \cdot 12 \pm 0.02$ & $7 \cdot 13 \pm 0.01$ & NS \\
$\quad$ (mean \pm SEM) & $42 \pm 2.6$ & $38 \pm 1 \cdot 7$ & NS \\
Lowest PaO in first 4 days & & & \\
$\quad$ (mean \pm SEM) & & & \\
Number of infants & $3(21)$ & $3(11)$ & NS \\
$\quad$ With septicaemia & $12(86)$ & $18(64)$ & NS \\
With patent ductus arteriosus & $8(57)$ & $9(32)$ & NS \\
$\begin{array}{l}\text { On indomethacin treatment } \\
\text { With bronchopulmonary dysplasia }\end{array}$ & $6(43)$ & $4(14)$ & NS \\
\hline
\end{tabular}

Percentages are given in parentheses.

Table 5 Factors associated with oxygen therapy

\begin{tabular}{|c|c|c|c|}
\hline & $\begin{array}{l}R L F \text { infants } \\
(n=14)\end{array}$ & $\begin{array}{l}\text { Controls } \\
(n=28)\end{array}$ & $\boldsymbol{P}$ \\
\hline $\begin{array}{l}\text { Oxygen administration (days, } \\
\text { mean } \pm \text { SEM) } \\
22-29 \% \\
30-59 \% \\
60-89 \% \\
90-100 \%\end{array}$ & $\begin{array}{l}53 \pm 11 \\
15 \pm 2 \\
36 \pm 10 \\
1 \cdot 6 \pm 0 \cdot 7 \\
0 \cdot 4 \pm 0 \cdot 2\end{array}$ & $\begin{array}{l}36 \pm 8 \\
19 \pm 4 \\
18 \pm 4 \\
1 \cdot 3 \pm 0 \cdot 6 \\
0 \cdot 3 \pm 0 \cdot 1\end{array}$ & $\begin{array}{l}\text { NS } \\
\text { NS } \\
\text { NS } \\
\text { NS } \\
\text { NS }\end{array}$ \\
\hline $\begin{array}{l}\text { Assisted ventilation (days, } \\
\text { mean } \pm \text { SEM) } \\
\text { No of } \mathrm{PaO}_{2} \text { readings (mean } \pm \text { SEM) }\end{array}$ & $30 \pm 6$ & $17 \pm 4$ & NS \\
\hline $\begin{array}{l}\text { In } 1 \text { st week } \\
\text { In } 2 \text { nd week } \\
\text { Total no }\end{array}$ & $\begin{array}{l}36 \pm 4 \\
18 \pm 4 \\
90 \pm 17\end{array}$ & $\begin{array}{l}36 \pm 3 \\
11 \pm 2 \\
56 \pm 7\end{array}$ & $\begin{array}{l}\text { NS } \\
\text { NS } \\
<0.05\end{array}$ \\
\hline $\begin{array}{l}\text { No of } \mathrm{PaO}_{2} \text { per day of oxygen } \\
\text { therapy (mean } \pm \text { SEM) } \\
\quad>80 \mathrm{mmHg} \\
>100 \mathrm{mmHg} \\
>120 \mathrm{mmHg}\end{array}$ & $\begin{array}{l}2 \pm 0 \cdot 3 \\
21 \pm 4 \\
8 \pm 1 \\
4 \pm 1\end{array}$ & $\begin{array}{l}3 \pm 0 \cdot 3 \\
15 \pm 2 \\
7 \pm 1 \\
4 \pm 1\end{array}$ & $\begin{array}{l}\text { NS } \\
\text { NS } \\
\text { NS } \\
\text { NS }\end{array}$ \\
\hline $\begin{array}{l}\text { Transcutaneous oxygen monitoring } \\
\text { (days, mean } \pm \text { SEM) } \\
\text { Exchange transfusion (n) }\end{array}$ & $\begin{array}{l}14 \pm 6 \\
3(21 \%)\end{array}$ & $\begin{array}{l}12 \pm 4 \\
6(21 \%)\end{array}$ & $\begin{array}{l}\text { NS } \\
\text { NS }\end{array}$ \\
\hline $\begin{array}{l}\text { Number of blood transfusions } \\
\text { (mean } \pm \text { SEM) }\end{array}$ & $7 \pm 1 \cdot 4$ & $4 \pm 0.6$ & $<0.05$ \\
\hline $\begin{array}{l}\text { Volume of blood transfused } \\
(\text { mean } \pm \text { SEM) }\end{array}$ & $115 \pm 29$ & $67 \pm 9$ & $<0.05$ \\
\hline
\end{tabular}




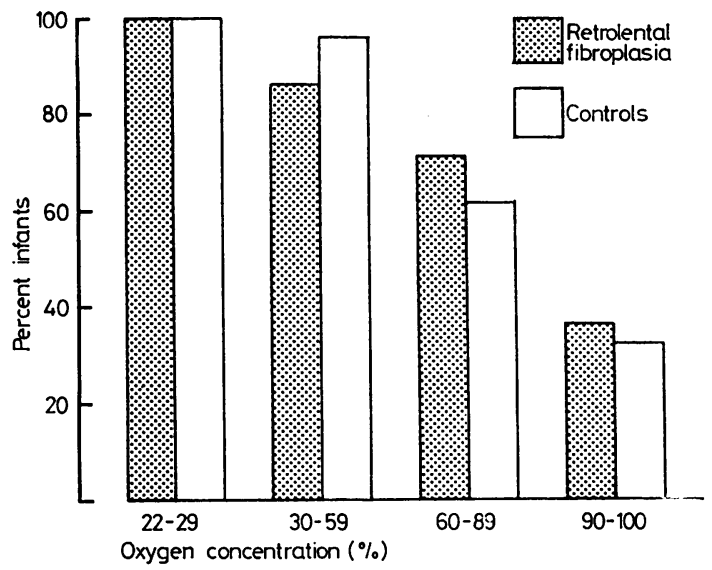

Fig. 1 Percentage of infants with retrolental fibroplasia and controls who were exposed to concentration of oxygen equal to or exceeding the range shown on abscissa.

of exposure to these ranges of oxygen concentration was also not significantly different between the two groups (Table 5) indicating that the average concentration of oxygen administered to RLF infants and controls was comparable. No significant difference was observed in the duration of assisted ventilation between the two groups, although the mean duration was longer for RLF infants.

An indication of the frequency with which $\mathrm{PaO}_{2}$ was measured is shown in Fig. 2, which is a plot of the average number of $\mathrm{PaO}_{2}$ readings per day for each RLF and control infant during the first 14 days of age. Although there was a slightly disproportionate decrease in the number of $\mathrm{PaO}_{2}$ readings with increasing age in both groups, the number of $\mathrm{PaO}_{2}$ readings in the second week was not significantly different between either group (Table 5). RLF infants had significantly more total $\mathrm{PaO}_{2}$ readings during their period on oxygen therapy compared with controls. The average number of $\mathrm{PaO}_{2}$ readings per day of oxygen therapy was however not significantly different. The duration of transcutaneous oxygen monitoring received by infants in both groups was also similar.

No significant differences were observed in the number of $\mathrm{PaO}_{2}$ readings $>80 \mathrm{mmHg},>100 \mathrm{mmHg}$, or $>120 \mathrm{mmHg}$ between the two groups (Table 5). Values of all $\mathrm{PaO}_{2}$ readings were analysed separately for RLF infants and controls with respect to the percentage distribution of $\mathrm{PaO}_{2}$ levels that were equal to or exceeding progressively higher increments (Fig. 3). It is evident that at levels of $\mathrm{PaO}_{2}$ exceeding $60 \mathrm{mmHg}, \mathrm{PaO}_{2}$ values for RLF infants were slightly lower than those of controls but the differences were negligible.

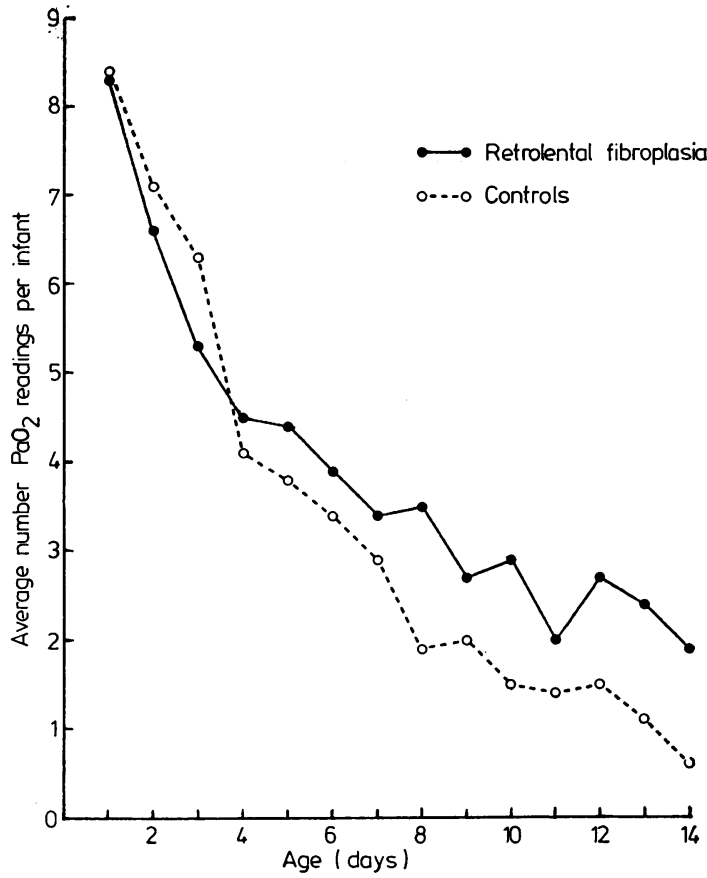

Fig. 2 Average number of $\mathrm{PaO}_{2}$ readings per day for each infant with retrolental fibroplasia and control infant in the first 14 days of age.

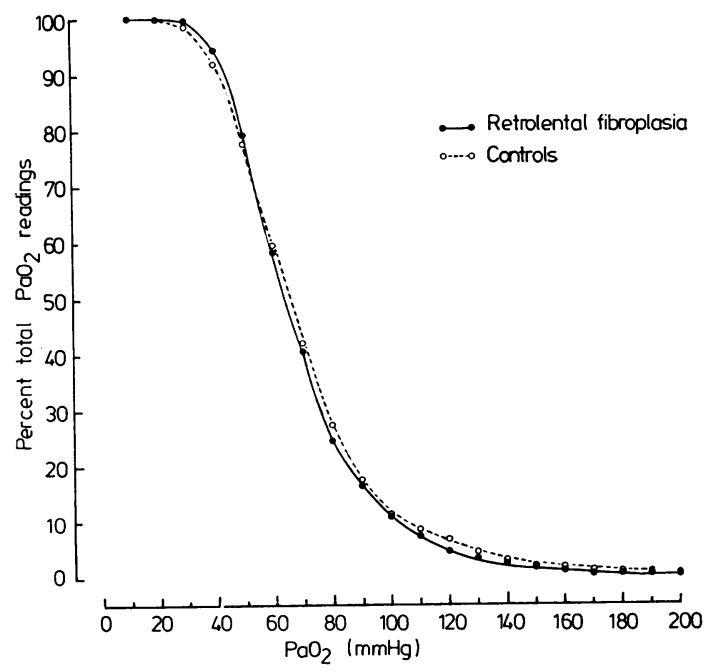

Fig. 3 Percentage of all $\mathrm{PaO}_{2}$ readings equal to or exceeding $\mathrm{PaO}_{2}$ levels shown on abscissa for all infants with retrolental fibroplasia and controls. 
Both the amount of blood transfused and the number of blood transfusions were significantly associated with RLF (Table 5). The percentage of RLF infants and controls who received exchange transfusions was low and identical in both groups.

\section{Discussion}

General curtailment of oxygen therapy, beginning in the mid 1950s, resulted in a decrease in incidence of RLF but an increase in mortality due to hyaline membrane disease, ${ }^{23}$ in incidence of cerebral palsy, ${ }^{24}$ and in number of deaths among preterm infants. ${ }^{25} 26$ Subsequent advances in neonatal intensive care methods and increased survival of small and criticallyill preterm infants appear to have led to a resurgence of RLF. ${ }^{27}$ RLF occurred in $32(37 \%)$ of 86 survivors under $1201 \mathrm{~g}$ birthweight in the 1969 to 1972 cooperative study ${ }^{3}$ and in $27(34 \%)$ of 80 survivors of under $1501 \mathrm{~g}$ birthweight from a 1975 to 1976 cohort. $^{2}$ The survival rate in the former study was unknown and that for the latter study was $60 \cdot 5 \%$. In a more recent study carried out in 1977 and 1978, $10(12 \%)$ of 82 infants examined with birthweights under $1601 \mathrm{~g}$ and $15(11 \%)$ of 134 infants examined with birthweights under $1501 \mathrm{~g}$ from two separate patient populations were reported to have RLF. ${ }^{17}$ However not all admissions in the respective birthweight categories were included in the study and the survival rate of these VLBW populations was unknown. Results of the present study, which showed an incidence of 3.5\% (14 of 375 infants) in all the VLBW infants admitted for neonatal intensive care or $4.7 \%$ (14 of the 297 infants) in the VLBW survivors, are encouraging. This is particularly so when considered in the light of improved survival during the study period, when the overall VLBW survival rate was $79.2 \%: 60$ (56\%) of 107 infants $501-1000 \mathrm{~g}$ birthweight and $237(88 \%)$ of 268 infants 1001-1500 g birthweight. Nevertheless, RLF continues to occur in the small preterm infant despite careful attention to oxygen therapy and monitoring. This is true even in the most advanced neonatal intensive care units where the administration of oxygen is strictly controlled by means of serial measurement of arterial oxygen tension and continuous transcutaneous oxygen monitoring.

The classification for RLF suggested by Reese et al. ${ }^{28}$ is no longer satisfactory for grading peripheral changes as seen by indirect ophthalmoscopy and a new scheme for acute RLF has been suggested by Kingham. ${ }^{18}$ Keith's modification ${ }^{17}$ of the Kingham's classification for the evolutionary lesions has been found to be clinically useful in the management of cases. The observed cicatricial changes do not easily fall into the grades described by Reese et al..$^{28}$ and the suggested classification by Keith ${ }^{17}$ which was used in this study conforms better to the findings of Faris et al. ${ }^{29}$ Infants with minimal peripheral changes (stages I and II) generally showed spontaneous resolution to normal within 4 months as has been found in previous studies. ${ }^{17} 18$ When the disease progressed to late stage III, resolution took longer and did so in a less predictable manner. It is therefore incumbent on the ophthalmologist to watch these infants closely until there are clear signs of resolution or until the disease process is no longer active.

The number of infants of multiple birth with RLF in the present study, unlike those in an earlier cooperative study ${ }^{30}$ but similar to those in the second co-operative study, ${ }^{3}$ was not significantly higher than that in the controls. This could be related to the much lower frequency of severe cases of RLF or to lack of sufficient numbers of infants of multiple birth. No association was found in this study between RLF and several factors which reflect the severity of neonatal illness-such as perinatal asphyxia, acidosis, hypoxaemia, and septicaemiaunlike the findings of an earlier study. ${ }^{2}$ RLF is a vascular disorder of the developing retinal arteries caused by vasoconstriction ${ }^{3}$ and the effect of treatment with indomethacin for patent ductus arteriosus on the retinal circulation of preterm infants is unknown. Our data supported that of an earlier study $^{31}$ that indomethacin does not increase the risk of RLF.

Although infants who developed RLF had a mean duration of oxygen therapy and assisted ventilation longer than that in controls, the differences were not statistically significant in the present study. Lack of a definitive relationship between $\mathrm{PaO}_{2}$ and RLF may stem from the qualitative and quantitative limitations of available data obtained from intermittent analyses of $\mathrm{PaO}_{2}$ levels. Although the use of continuous transcutaneous oxygen monitoring was promising as a means of establishing better dose-time relationships between $\mathrm{PaO}_{2}$ and RLF, the availability of only 4 such monitors in a neonatal unit in which at least 15 preterm infants could simultaneously be on oxygen therapy, of whom up to 7 might require assisted ventilation, has meant that such infants received this form of monitoring only for intermittent periods.

An association between RLF and the amount of blood transfused was observed in this study. The higher affinity of fetal haemoglobin for oxygen owing to a quantitative reduction in the amount of 2,3diphosphoglycerate in fetal red blood cells tends to protect against hyperoxaemia in requiring a higher $\mathrm{PaO}_{2}$ before unloading at the tissue level occurs. The replacement of fetal by adult haemoglobin as a result of blood transfusions would decrease the 
haemoglobin-oxygen affinity and theoretically increase the risk of RLF by facilitating tissue oxygen toxicity at lower $\mathrm{PaO}_{2}$ levels. Conflicting reports concerning the role of blood transfusions date back to $1950 .^{32}$ Although subsequent studies found no association between transfusions and $R L F,{ }^{33-35}$ renewed interest in the possible role of replacement or exchange transfusions in the pathogenesis of $R_{L F}^{2} 51536$ indicates that this factor deserves fuller in-depth study.

Oxygen therapy for preterm infants remains a balanced risk: death or brain damage from too little oxygen or blindness from too much. With currently available technology, even the most impeccable monitoring of arterial oxygen tension with serial samples complemented with transcutaneous oxygen measurements does not guarantee against RLF. As RLF continues to be an unavoidable risk of neonatal intensive care, the need remains for vigilance on oxygen therapy and associated risk factors in its pathogenesis.

\section{References}

1 American Academy of Pediatrics Committee on Fetus and Newborn. History of oxygen therapy and retrolental fibroplasia. Pediatrics 1976; 57: Supplement 2, 591-642.

2 Gunn T R, Easdown J, Outerbridge E W, Aranda J V. Risk factors in retrolental fibroplasia. Pediatrics 1980; 65: 1096-100.

${ }^{3}$ Kinsey V E, Arnold $\mathrm{H}$ J, Kalina R E, et al. $\mathrm{PaO}_{2}$ levels and retrolental fibroplasia: a report of the co-operative study. Pediatrics 1977; 60: 655-68.

4 Anonymous. Retrolental fibroplasia (RLF) unrelated to oxygen therapy. $\mathrm{Br} J$ Ophthalmol 1974; 58: 487-9.

5 Adamkin D H, Shott R J, Cook L N, Andrews B F. Nonhyperoxic retrolental fibroplasia. Pediatrics 1977; 60: $828-30$.

6 Karlsberg R C, Green W R, Patz A. Congenital retrolental fibroplasia. Arch Ophthalmol 1973; 89: 122-3.

7 Stefani F H, Ehalt $H$. Non-oxygen induced retinitis proliferans and retinal detachment in full-term infants. Br J Ophthalmol 1974; 58: 490-513.

8 Kraushar M F, Harper R G, Sia C G. Retrolental fibroplasia in a full term infant. Am J Ophthalmol 1975; 80: 106-8.

9 Addison D J, Font R L, Manschot W A. Proliferative retinopathy in anencephalic babies. Am $J$ Ophthalmol 1972; 74: 967-76.

10 Kalina R E, Hodson W A, Morgan B C. Retrolental fibroplasia in a cyanotic infant. Pediatrics 1972; 50: 765-8.

11 Aranda J V, Sweet A Y. Sustained hyperoxemia without cicatricial retrolental fibroplasia. Pediatrics 1974; 54: 434-7.

12 Kinsey V E, Zacharias L. Retrolental fibroplasia: incidence in different localities in recent years and a correlation of the incidence with treatment given the infants. JAMA 1949; 139: 572-8.

13 Johnson L, Schaffer D B, Blesa M I, Boggst R. Factors predisposing to RLF: complications of pregnancy (abstract). Pediatr Res 1978; 12: 527.

14 Johnson L H, Schaffer D B, Goldstein D E, Boggst R. Influence of vit $\mathrm{E}$ treatment $(\mathrm{Rx})$ and adult blood transfusions on mean severity of retrolental fibroplasia in premature infants (abstract). Pediatr Res 1977; 11: 535.
15 Aranda J V, Clark T E, Maniello R, Outerbridge E W. Blood transfusion (BT): possible potentiating risk factor in retrolental fibroplasia (abstract). Pediatr Res 1975; 9: 362.

16 Schrager G O. Letter: PDAs, prostaglandins, and RLF. Pediatrics 1978; 62: 860-1.

17 Keith C G. Retrolental fibroplasia, a new classification of the developing and cicatricial changes. Aust J Ophthalmol 1979; 7: 189-94.

18 Kingham J D. Acute retrolental fibroplasia. Arch Ophthalmol 1977; 95: 39-47.

19 Yu V Y H, Hollingsworth E. Respiratory failure in infants weighing $1000 \mathrm{~g}$ or less at birth. Aust Paediatr $J$ 1979; 15: 152-9.

20 Yu V Y H, James B, Hendry P, MacMahon R A. Total parenteral nutrition in very low birthweight infants: a controlled trial. Arch Dis Child 1979; 54: 653-1.

$21 \mathrm{Yu} \mathrm{V} \mathrm{Y} \mathrm{H,} \mathrm{Hollingsworth} \mathrm{E.} \mathrm{Improving} \mathrm{prognosis} \mathrm{for}$ infants weighing $1000 \mathrm{~g}$ or less at birth. Arch Dis Child $1980 ; 55$ : 422-6.

22 Obeyesekere H I, Pankhurst S, Yu V Y H. Pharmacological closure of ductus arteriosus in preterm infants using indomethacin. Arch Dis Child 1980; 55: 271-6.

23 Avery M E, Oppenheimer E H. Recent increase in mortality from hyaline membrane disease. $J$ Pediatr 1960; 57: 553-9.

24 McDonald A D. Cerebral palsy in children of very low birthweight. Arch Dis Child 1963; 38: 579-88.

25 Cross $\mathrm{K}$ W. Cost of preventing retrolental fibroplasia? Lancet 1973; ii: 954-6.

26 Boulton D P G, Cross K W. Further observations on cost of preventing retrolental fibroplasia. Lancet 1974; i: $445-8$.

27 Svedbergh B, Lindstedt E. Retrolental fibroplasia in Sweden. Acta Paediatr Scand 1973; 62: 458-64.

28 Reese A B, King M J, Owens W C. A classification of retrolental fibroplasia. Am J Ophthalmol 1953; 36: 1333-5.

${ }^{29}$ Faris B M, Tolentino F I, Freeman H M, Brockhurst R J, Schepens C L. Retrolental fibroplasia in the cicatricial stage. Arch Ophthalmol 1971; 85: 661-8.

30 Kinsey V E. Retrolental fibroplasia: co-operative study of retrolental fibroplasia and the use of oxygen. Arch Ophthalmol 1956; 56: 481-543.

31 Procianoy R S, Garcia-Prats J A, Hittner H M, Adams J M, Rudolph A J. Use of indomethacin and its relationship to retinopathy of prematurity in very low birthweight infants. Arch Dis Child 1980; 55: 362-4.

32 Mallek H, Spohn P H. Retrolental fibroplasia. Can Med Assoc $J$ 1950; 63: 586-8.

33 Exline A L, Jr, Harrington M R. Retrolental fibroplasia: clinical statistics from the premature centre of the Charity Hospital of Louisiana at New Orleans. $J$ Pediatr $1951 ; 38: 1-7$.

34 Dancis J, Lewis J M, Guy L P. Retrolental fibroplasia: a statistical study with particular reference to the effect of vitamin A. $N$ Engl J Med 1951 ; 245: 402-6.

35 Ryan H. Retrolental fibroplasia: a clinicopathologic study. Am J Ophthalmol 1952; 35: 329-42.

36 Bard H, Cornet A, Orquin J, Doray B H. Retrolental fibroplasia and exchange transfusions (abstract). Pediatr Res 1975; 9: 362.

Correspondence to Dr V Y H Yu, Department of Paediatrics, Queen Victoria Medical Centre, 172 Lonsdale Street, Melbourne, Victoria 3000, Australia.

Received 22 June 1981 